\title{
Transatlantic Panel on Research and Implementation for eTraining and eLearning
}

\author{
Chair: Raymond Morel $(\mathrm{CH})$ \\ Panel: John Cherniavsky (US), Harriet Taylor (US), Rick Adrian (US), Jens \\ Christiansen (DK/EU), Jan Hylen (SE/EUN), Bernard Cornu (FR), \\ Pieter Hogenbirk (NL), Doug Brown (UK)
}

Keywords: distance learning, research, learning models, collaboration and international cooperation, national programme

Following a brief overview of the different types of research and that the emphasis here would be on research which led to practical outcomes, the speakers - and the discussion which followed - covered a wide range of projects and proposals.

A number of joint ways of working are possible and indeed some current developments in the USA had potential for collaboration with activities in the EU. Three main themes emerged.

- Development of a learning grid (based on the experience from other domains but available for researchers and educators in both the USA, EU and elsewhere).

- Exchanges and visits to share and learn from each other.

- The provision of effective educational resources through the creation of artefact repositories.

The development of a learning grid is not in itself a new idea. The UK has their 'National Grid for Learning' and the EU has developed an educational portal for the exchange of ideas. However, the emphasis on research would lead this grid to offer something different. The idea of a community of learners was discussed and that the concept of collective intelligence underpinned this. The Internet allows for a new scale for addressing problems and for sharing ideas such as how ICT can make a 
difference to learning and student performance. The learning grid could support small research experiments in different countries and it could also support larger change. In the USA the average adult would now change jobs 6 times in their lifetime and there is a need to ensure the ability to continue learning if we are to be able to adapt to this environment. The challenge is to seek research which will lead to a revolutionary change rather than an evolutionary one.

There is already a formal agreement between the USA and the EU signed in December 1997. This determined to synchronise projects across the Atlantic, run joint seminars and arrange visits and exchanges. Joint programmes already exist - such as a project on the school of the future and the 'learning citizen'. There is a move towards increased cooperation in this area, with a desire to see exchanges of both researchers and students.

Work is currently underway in the USA on a digital library which will be operational by the latter part of 2002. The aim is to move from 'great piles of stuff 'to 'piles of great stuff. This will be available to the international community and will seek to build on work in other areas. There is a desire to hear from others and collaborate on this work.

All these developments were generally welcomed by the group. New technology means new pedagogy, and this needs to reflect the shift from computer/informatics to communication and information in society. We need to practice what we preach, recognise that early adopters and innovators may provide and get a good personal feeling but we need to focus on the majority.

Being at the leading edge has a number of pitfalls but an EU seminar identified that governments' needed to a) move fast b) be bold and c) learn from each other. This collaboration across the Atlantic could be a key factor in enabling them to do this. 